\title{
Chapter 9 Synthesis of TRIP Matrix Composites by Field Assisted Sintering Technology—Challenges and Results
}

\author{
Sabine Decker, Markus Radajewski and Lutz Krüger
}

\begin{abstract}
This chapter analyses options to synthesis TRIP matrix composites (reinforced with Mg-PSZ), which stand out due to a high strength and the possibility to undergo a stress- and strain-induced phase transformation. These composites are processed using Field Assisted Sintering Technology (FAST). Both, the influence of the powder treatment before sintering and the impact of parameter setting during sintering by FAST are discussed. Due to a careful alignment of these factors, a TRIP matrix composite (reinforced with 5 vol\% Mg-PSZ) with an $1 \%$ compressive yield strength of $700 \mathrm{MPa}$ was generated. Furthermore, both composite components exhibited a phase transformation during compressive deformation. The fundamental investigations are the basis for the development of Functionally Graded Materials (FGM) with a varying Mg-PSZ content along the sample height. To synthesize these FGMs by FAST, a temperature gradient has to be generated during sintering, which allows to sinter the pure ceramic layer without melting the steel phase. Several possibilities to generate a temperature gradient are discussed.
\end{abstract}

\subsection{Introduction}

With the aim to develop a composite material with a high strength while keeping a sufficient ductility and toughness, a Transformation Induced Plasticity (TRIP) steel was combined with MgO Partially Stabilized Zirconia (Mg-PSZ). Both materials have the ability to undergo a phase transformation, if a certain stress or deformation is applied, which improves strength and toughness. TRIP steels have the possibility to transform from austenite into $\alpha^{\prime}$-martensite, if a certain trigger stress is reached.

\footnotetext{
S. Decker (Emeritus)

Institute of Materials Engineering, Technische Universität Bergakademie Freiberg, Gustav-Zeuner-Straße 5, 09599 Freiberg, Germany

M. Radajewski · L. Krüger $(\varangle)$

Institute of Materials Engineering, Technische Universität Bergakademie Freiberg, Gustav-Zeuner-Straße 5, 09599 Freiberg, Germany

e-mail: krueger@ww.tu-freiberg.de 
Under this requirement, the $\alpha^{\prime}$-martensite content increases with ongoing deformation. The $\alpha^{\prime}$-martensite nuclei form mainly in deformation bands and restrict the dislocation movement. This leads to an increase in material strength similar to grain refinement [1-3].

Due to the partial stabilization with $\mathrm{MgO}$, the high temperature phases (cubic and tetragonal) of zirconia are stable at room temperature in Mg-PSZ [4]. If a certain stress is applied, the tetragonal phase transforms into the monoclinic phase. This phase transformation comes along with a volume expansion, which is able to close cracks and introduces compressive stresses to the surrounding area [5]. This effect is used to improve the toughness of ceramic materials. The combination of both materials, the TRIP steel and the Mg-PSZ, holds the possibility to get a composite with a high strength and still a high ductility and toughness. Furthermore, it is assumed, that both phase transformations trigger each other [6].

A promising technique to process high-strength materials on a powder metallurgical route is the Field Assisted Sintering Technology (FAST), known as Spark Plasma Sintering, as well. This sintering technique is similar to hot pressing. That means, the powder is uniaxially compressed inside a die during sintering. However, heat is generated directly in the powder and/or in the sintering tool by an electric current, running through the electrically conductive powder and/or the electrically conductive die. Depending on the producer of the FAST device, the electric current is an alternating current or a direct current, which can be pulsed or continuous. The current passes merely through the electrically conductive die, if the powder is electrically nonconductive [7]. If the current runs through the powder, especially powder particle contacts are areas with a high electrical resistivity, which cause an extreme rise in temperature. Hence, the heat is generated at locations where it is most needed. Due to the heat generation directly within the powder or close to the powder, very fast heating rates can be attained and dwell times can be kept short [7,8]. Caused by the short sintering process, diffusion driven mechanisms like grain growth and formation of precipitations or solid solutions occur in a reduced manner [7, 8]. Hence, extraordinary microstructures can be achieved and the sintered material exhibits a high strength due to its small grains.

Composites consisting of stainless steel and yttria stabilized zirconia were already sintered by FAST [9-11]. However, none of these studies addressed the effect of FAST parameters on microstructure and in none of these studies phase transformations under mechanical loading in both, in metastable stainless steel and in PSZ, were tried to achieve. However, to develop a high strength material it is important to understand how steel and ceramic influence each other and how the process parameters control the microstructural evolution and the achieved mechanical properties. Since 2008, researchers at TU Bergakademie Freiberg/Germany comprehensively investigate Mg-PSZ reinforced TRIP matrix composites in a collaborative research center (CRC 799). Among other topics, the influence of sintering parameters during FAST, chemical composition of the steel matrix and homogeneity of the composite powder on microstructural evolution and mechanical properties were studied. Based on the results, it was possible to develop a composite material with a high strength and sufficient ductility, where both composite constituents experienced a phase transformation under mechanical loading. Furthermore, the results are the basic principles for 
the processing of functionally graded materials (FGMs). To sinter FGMs by FAST, several possibilities to adjust temperature gradients during FAST were investigated. The achieved results are presented in the next paragraphs.

\subsection{Experimental Methods}

For FAST experiments, different steel (Table 9.1) and Mg-PSZ powders (Table 9.2) were used. The distribution of powder particle size of different powders is shown in Table 9.3. Due to the complexity of nomenclature, the steel and the Mg-PSZ powders are abbreviated with S1-6 and Z1-3, respectively (see Tables 9.1 and 9.2).

The powders Z1, Z2 and Z3 are commercial powders from Saint-Gobian. While the steel powders S1, S5 and S6 were gas atomized by TLS Technik GmbH \& Co. Spezialpulver KG (Bitterfeld/Germany), the powders S2, S3 and S4 were gas atomized at the Institute of Iron and Steel Technology at TU Bergakademie Freiberg (Germany). The steel powders consisted of austenite and $\alpha^{\prime}$-martensite. As the $\alpha^{\prime}$ martensite completely transforms to austenite during sintering, an exact indication of $\alpha^{\prime}$-martensite within the steel powder is not required.

Table 9.1 Chemical composition of the steel powders

\begin{tabular}{l|l|l|l|l|l|l|l|l}
\hline$[\mathrm{wt} \%]$ & $\mathrm{Cr}$ & $\mathrm{Mn}$ & $\mathrm{Ni}$ & $\mathrm{Si}$ & $\mathrm{N}$ & $\mathrm{C}$ & $\mathrm{S}$ & $\mathrm{Fe}$ \\
\hline PM X3CrMnNi16-6-6 \\
\hline S1 & 16.40 & 6.30 & 6.30 & 1.00 & 0.06 & 0.03 & 0.01 & Bal. \\
\hline PM X5CrMnNi14-6-5 \\
\hline S2 & 14.37 & 5.98 & 5.46 & 0.97 & 0.05 & 0.05 & 0.02 & Bal. \\
\hline PM X3CrMnNi14-7-8 \\
\hline S3 & 14.20 & 7.98 & 8.40 & 0.94 & 0.03 & 0.03 & 0.02 & Bal. \\
\hline S4 & 14.08 & 6.68 & 8.99 & 0.94 & 0.04 & 0.04 & 0.10 & Bal. \\
\hline PM X4CrMnNi16-6-6 \\
\hline S5 & 16.10 & 5.96 & 5.97 & 0.89 & 0.04 & 0.04 & 0.01 & Bal. \\
\hline PM X4CrMnNi16-7-3 \\
\hline S6 & 15.60 & 7.10 & 3.03 & 0.01 & 0.05 & 0.04 & 0.01 & Bal. \\
\hline PM X2CrMnNi16-7-6 & 16.40 & 7.10 & 6.30 & 0.11 & 0.06 & 0.02 & 0.00 & Bal. \\
\hline S7
\end{tabular}

Table 9.2 Chemical analysis of the Mg-PSZ powders

\begin{tabular}{l|l|l|l|l|l|l|l|l}
\hline$[\mathrm{wt} \%]$ & $\mathrm{SiO}_{2}$ & $\mathrm{MgO}$ & $\mathrm{Al}_{2} \mathrm{O}_{3}$ & $\mathrm{CaO}$ & $\mathrm{TiO}_{2}$ & $\mathrm{Na}_{2} \mathrm{O}$ & $\mathrm{Fe}_{2} \mathrm{O}_{3}$ & $\mathrm{ZrO}_{2}$ \\
\hline $\mathrm{Z} 1$ & 4.23 & 3.37 & 0.63 & 0.21 & 0.14 & 0.09 & 0.1 & Bal. \\
\hline $\mathrm{Z} 2$ & 0.41 & 2.82 & 0.38 & 0.15 & 0.13 & 0.10 & 0.13 & Bal. \\
\hline $\mathrm{Z3}$ & 0.10 & 3.25 & 1.58 & 0.06 & 0.13 & - & 0.02 & Bal. \\
\hline
\end{tabular}


Table 9.3 Powder particle size distribution

\begin{tabular}{|c|c|c|c|}
\hline Powder & $d_{10}[\mu \mathrm{m}]$ & $d_{50}[\mu \mathrm{m}]$ & $d_{90}[\mu \mathrm{m}]$ \\
\hline \multicolumn{4}{|l|}{ TRIP steel } \\
\hline S1 & 7.4 & 20.7 & 41.3 \\
\hline $\mathrm{S} 2<25 \mu \mathrm{m}$ & 6.1 & 12.3 & 21.4 \\
\hline $\mathrm{S} 225-45 \mu \mathrm{m}$ & 11.7 & 24.1 & 36.9 \\
\hline $\mathrm{S} 245-63 \mu \mathrm{m}$ & 13.1 & 38.4 & 56.2 \\
\hline S3 & 10.8 & 37.3 & 124.2 \\
\hline S4 & 5.5 & 17.1 & 103.6 \\
\hline S5 & 10.3 & 28.1 & 44.4 \\
\hline S6 & 7.8 & 19.9 & 33.0 \\
\hline S7 & 12.4 & 25.9 & 46.6 \\
\hline \multicolumn{4}{|l|}{$M g-P S Z$} \\
\hline $\mathrm{Z1}$ & 0.1 & 1.3 & 10.8 \\
\hline $\mathrm{Z} 2$ & 0.2 & 3.1 & 22.4 \\
\hline $\mathrm{Z3}$ & 13.4 & 21.1 & 32.9 \\
\hline
\end{tabular}

The powder Z1 exhibited 10 vol\% monoclinic, 37 vol\% tetragonal and 53 vol\% cubic phase, while the powder Z2 contained $35 \mathrm{vol} \%$ monoclinic, 32 vol\% tetragonal and 33 vol\% cubic phase. Only 1 vol\% monoclinic phase was present in powder Z3 while $38 \mathrm{vol} \%$ were in the tetragonal and $68 \mathrm{vol} \%$ were in the cubic phase.

Composite powders with varying Mg-PSZ contents were mixed in a planetary ball mill PULVERISETTE 6 classic line (FRITSCH GmbH, Germany). For mixing, steel balls with a diameter of $10 \mathrm{~mm}$ were used and a ball mass to powder mass ratio of 5:1 was applied. Mixing was carried out for four hours. To achieve a sufficient swirling of the powder, the rotation speed was calculated by using (9.1) [12] depending on used milling vessel size to be 100 or $110 \mathrm{rpm}$ for simply homogenization. A rotation speed of $250 \mathrm{rpm}$ was utilized for high energy milling. Merely, the composite powders that are based upon S6 and Z2 were mixed in a PET vessel for one hour, using yttria stabilized zirconia balls.

$$
N_{0}=\frac{32}{\sqrt{d}}
$$

$N_{0}$ rotation speed in rpm

$d$ diameter of milling vessel in meter.

Afterwards, pure steel samples, pure Mg-PSZ samples, composites with constant Mg-PSZ volume content (5\%, 10\% or 40\%) and FGMs with varying Mg-PSZ content were sintered. FGMs were prepared by layering composite powders with decreasing Mg-PSZ content on top of each other inside a graphite die. Unless specified otherwise, all sintering experiments were carried out using a FAST device HP D 25 (FCT Systeme GmbH, Germany). To start the sintering process, it is necessary to apply at 
least a uniaxial load of $5 \mathrm{kN}$. Thus, a complete pressureless sintering is not possible in this device. All performed sintering cycles were carried out under fine vacuum and the cooling process after sintering was unregulated by simply switching off the power supply. The used dies and punches consisted of graphite (type 2333 from Mersen, Germany). After sintering, the relative density of the sintered samples was determined by Archimedes density measurements. Considering thermal expansion and elastic deformation of powder and punches during sintering, the evolution of the relative density during sintering was calculated in accordance to [13] by using (9.2).

$$
\rho_{i}=\rho_{0} \cdot e^{\varepsilon_{z i}}
$$

$\rho_{i} \quad$ density at time $i$

$\varepsilon_{z i} \quad$ shrinkage in $z$-direction at time $i$

$\rho_{0} \quad$ initial density before sintering.

To investigate the mechanical properties under compressive loading conditions, cylindrical samples with a diameter to height ratio of 1:1 were machined and quasistatic compression tests $\left(10^{-3} \mathrm{~s}^{-1}\right.$, MTS 810$)$ were carried out to a maximum of $60 \%$ compressive deformation. Furthermore, hardness measurements were conducted in the layers of FGMs, using Vickers hardness at a load of 9.807 N (HV1). The microstructure of the as sintered samples and of the compressed samples was characterised by XRD measurements, light optical microscopy and scanning electron microscopy in combination with electron backscatter diffraction (EBSD).

\subsection{Results and Discussion}

\subsubsection{Influence of the Composite Powder on the Microstructural Evolution and Mechanical Properties of the Sintered Composite}

If the results of a sintering experiment are evaluated, they are not only a consequence of sintering parameters, set on the sintering device. They are a product of chemical composition and the earlier treatment of the material (e.g. mixing). Some aspects of such treatments and chemical variations, which could be used to set the powder into a good initial position to achieve a high-strength material, are discussed in this chapter.

First of all and very important, the chemical composition of the steel powder influences the phase composition of the composite. During sintering, the Mg-ions diffuse from the Mg-PSZ into the steel matrix [14]. Thus, the Mg-PSZ destabilizes and the monoclinic phase content increases. However, the alloying elements of the 
steel influence the Mg-PSZ as well. For example, Mn from the steel stabilizes MgPSZ [14, 15]. Accordingly, it is possible that the Mg-PSZ is destabilized during sintering by FAST depending on the steel matrix. If an PM X5CrNi18-10 was used as matrix material, which contains $0.96 \mathrm{wt} \% \mathrm{Mn}$, approximately $45 \mathrm{vol} \%$ of the $\mathrm{Mg}$ PSZ were destabilized during sintering [16]. However, if the steel matrix was similar to an PM X3CrMnNi16-6-6, only a few percent of the Mg-PSZ transformed to the monoclinic phase during sintering by FAST [17], as a consequence of the increased Mn content.

Less percentage of Mg-PSZ destabilized, if the Mg-PSZ content within the composite increased. Hence, no destabilization was measured, if pure Mg-PSZ was sintered [18]. Furthermore, the Mg-PSZ content influences the material properties, which the composite exhibits after sintering by FAST in general. Not only hardness and strength increase with increasing Mg-PSZ content (Fig. 9.1). Mg-PSZ particles have a pinning effect on the grain boundaries of the steel matrix. Thus, the grain growth within the steel phase is impeded with increasing Mg-PSZ fraction [16, 18]. Accordingly, the strength of the composite is not only a function of the Mg-PSZ content, but also of the grain size of the steel matrix as well. With decreasing steel grain size, the strength of the steel increases, which was already shown by the Hall-Petch relation [19].

In addition, the remaining porosity after sintering by FAST influences the material strength and the ductility [18]. However, the effect of porosity depends on the Mg-PSZ content, as well. Due to more steel-to-steel contacts, composites with a lower Mg-PSZ content exhibit a sufficient ductility, for example $80 \%$ true compressive strain for a composite reinforced with 5 vol\% Mg-PSZ and only $8 \%$ true compressive strain for a composite reinforced with $40 \mathrm{vol} \% \mathrm{Mg}$-PSZ (composites containing powders Z1 and S1, see Fig. 9.1) [18].

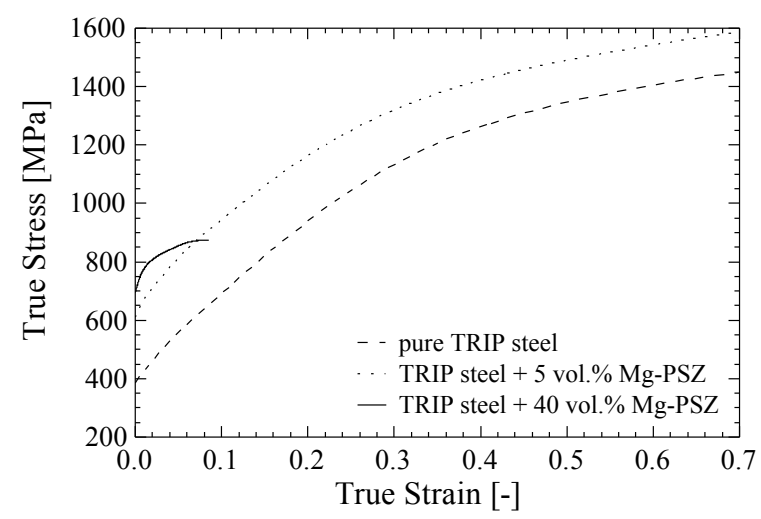

Fig. 9.1 Increase in compression strength with Mg-PSZ content $\left(10^{-3} \mathrm{~s}^{-1}\right)$ 


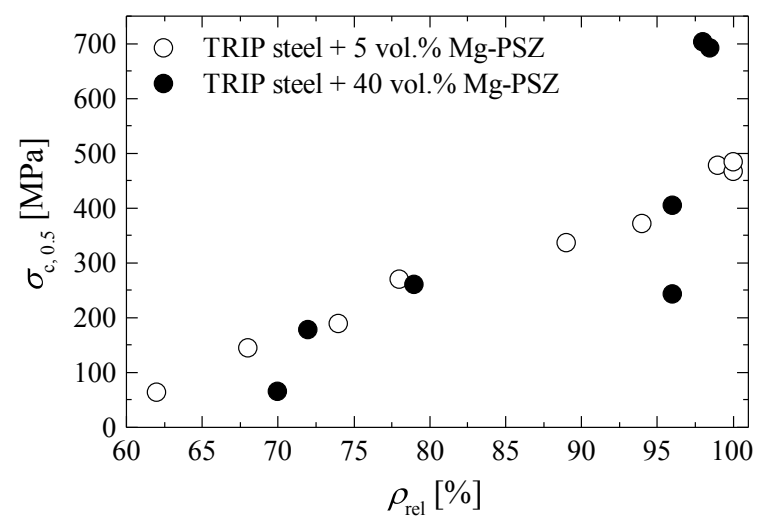

Fig. 9.2 Influence of relative density $\rho_{\text {rel }}$ on $0.5 \%$ compressive yield strength $\sigma_{\mathrm{c}, 0.5}$ of composites consisting of Mg-PSZ (Z1) and a TRIP steel (S1), sintered using various parameters

The same effect applies for porosity. Composites with a low Mg-PSZ content can be deformed up to $80 \%$ true compressive strain even with a porosity of $22 \mathrm{vol} \%$ [18]. However, strength drastically decreases with increasing porosity (Fig. 9.2) [18]. While the $0.5 \%$ compressive yield strength increases linearly with relative density for a composite with 5 vol\% Mg-PSZ, composites with 40 vol\% Mg-PSZ (composites containing powders $\mathrm{Z} 1$ and $\mathrm{S} 1$ ) exhibit a strong increase in $0.5 \%$ compressive yield strength for a relative density $>96 \%$. Besides, for the composites with $40 \mathrm{vol} \%$ Mg-PSZ, values for $0.5 \%$ compressive yield strength deviate more (Fig. 9.2).

This deviation is caused by weakly sintered Mg-PSZ clusters. For a large relative density the strong increase in $0.5 \%$ compressive yield strength is a result of an increase in interfacial strength of Mg-PSZ/steel interfaces. However, the present weakly sintered Mg-PSZ clusters are the initiation areas for failure and they appear more frequently in composites with a higher Mg-PSZ content [18].

Since the $\alpha^{\prime}$-martensite formation is strain-induced, $\alpha^{\prime}$-martensite content increased with ductility of the composite. Hence, maximum $10 \mathrm{vol} \% \alpha^{\prime}$-martensite was formed in composite material containing $40 \mathrm{vol} \% \mathrm{Mg}-\mathrm{PSZ}$ (containing S1 and $\mathrm{Z1}$ ), due to its brittle material performance [18]. With decreasing Mg-PSZ content, ductility increases and more $\alpha^{\prime}$-martensite is formed [20]. Besides, the content of strain-induced $\alpha^{\prime}$-martensite depends on the chemical composition of the steel matrix, as well $[16,17]$. However, a decrease in Mg-PSZ content does not lead necessarily to an increase in strain-induced $\alpha^{\prime}$-martensite [16]. As Martin et al. [6] proved, $\alpha^{\prime}$-martensite is formed preferential at poles of hard reinforcing particles under compressive deformation. Hence, a certain content of reinforcing phase triggers the $\alpha^{\prime}$-martensite formation. 
In contrast, pores diminish the $\alpha^{\prime}$-martensite formation. If a porous material is compressed, a large content of deformation is engaged with closing pores, which does not involve extensive formation of deformation bands. Deformation bands are the sites for $\alpha^{\prime}$-martensite nucleation [2, 21]. For a composite containing $5 \mathrm{vol} \% \mathrm{Mg}$-PSZ (consisting of S1 and Z1), a porosity $<10 \mathrm{vol} \%$ is necessary to form the maximum possible strain-induced $\alpha^{\prime}$-martensite content [18]. With increasing Mg-PSZ content, more Mg-PSZ clusters are formed, which are the origin of damage. Cracks run preferentially through Mg-PSZ clusters and along steel/Mg-PSZ interfaces [16-18]. Hence, the failure behavior becomes more brittle and less $\alpha^{\prime}$-martensite is generated.

Thus, to optimize ductility and strength, it is important to achieve a homogeneous distribution of the reinforcing phase within the matrix and to avoid clustering of the ceramic particles. This is possible by adjusting the particle sizes of matrix powder and reinforcing powder. That means, coarse Mg-PSZ powder is needed and the steel powder has to be refined. To get fine steel powder, it could be sieved to receive the fine fraction of gas atomized powder, or it could chemically be changed in a way to reduce the surface tension. This would lead to smaller particles during gas atomization [22].

However, the used powder particle size distribution influences the densification rate and grain size distribution of the compacted samples [1]. As demonstrated, using steel powder S2, which was sieved to fractions $<25 \mu \mathrm{m}, 25 \mu \mathrm{m}-45 \mu \mathrm{m}$ and $45 \mu \mathrm{m}-$ $63 \mu \mathrm{m}$, the densification rate slightly increased with decreasing particle size. Hence, it is possible to reduce dwell time during sintering by FAST with decreasing particle size [1]. While the steel powder (S2) with a particle size of 45-63 $\mu \mathrm{m}$ needed a dwell time of $4.3 \mathrm{~min}$, dwell time could be reduced to $3 \mathrm{~min}$ for the steel powder (S2) with a particle size $<25 \mu \mathrm{m}$ [1]. Furthermore, the maximum in shrinkage is shifted to slightly lower temperatures with decreasing particle size. Thus, the maximum sintering temperature can be reduced, as well [1]. With increasing particle size, it is most likely to get large grains, which can exceed the initial particle size, due to the strong overheating at the few particle contacts of the coarse powder particles [1]. Therefore, the powder mixture should contain a variety of particle sizes to facilitate a large number of powder particle contacts. Furthermore, small particles have small grains, which lead to an increased compressive yield strength due to the Hall-Petcheffect. However, the work hardening rate is higher in large grains due to a higher $\alpha^{\prime}$-martensite formation rate. In small grains, $\alpha^{\prime}$-martensite formation sets in at larger strain values compared to coarse grains. More energy is needed in small grains in comparison to larger grains to expand deformation bands, which are the locations for $\alpha^{\prime}$-martensite formation [1]. But after $60 \%$ compression, steel samples sintered from powder particles $<25 \mu \mathrm{m}$ exhibited a similar compressive strength like samples sintered from powder particles in the range of 45-63 $\mu \mathrm{m}$ [1].

Another possibility to reduce the steel particle size as a result of gas atomization is the reduction of the surface tension of liquid steel melt. Thus, smaller steel drops and thereby smaller steel particles are generated during gas atomization [22]. A possibility to reduce this surface tension is the addition of sulfur to the steel melt. Using the steels S3 (0.02 wt \% sulfur) and S4 (0.1 wt \% sulfur), the influence of sulfur content on microstructure and mechanical properties was investigated. The sulfur content 
did not influence the grain size of the steel matrix after sintering of unreinforced steel, due to the high driving force for grain growth in fine grained material [22]. In contrast, the grain size of the steel matrix varied with sulfur content in the composite material due to pinning of the grain boundaries by Mg-PSZ (reinforced with $10 \mathrm{vol} \%$ Mg-PSZ of Z1). A smaller grain size was measured, if the sulfur content within the composite material was high. The reinforcing Mg-PSZ particles impeded the grain growth and almost kept the grain size of the initial steel particles [23]. The sulfur formed precipitations during sintering by FAST. According to EBSD measurements, these precipitations were $\mathrm{CrS}, \mathrm{Cr}_{2} \mathrm{~S}_{3}$ and $\mathrm{MnS}$ [22]. The amount of precipitations increased with sulfur content and resulted in an increase of $40 \mathrm{MPa}$ in compressive yield strength and a rise in work hardening [22]. If the TRIP steel (S4) was reinforced with 10 vol\% Mg-PSZ (Z1), more than 50\% of the precipitations consisted of MnS and they were formed mainly at the steel/Mg-PSZ interfaces [23]. Due to the binding of $\mathrm{Mn}$ in precipitations, less Mn was on hand to stabilize the Mg-PSZ. Thus, more Mg-PSZ destabilized in steel matrix S4 during sintering [23]. Independent of the presence of reinforcement by Mg-PSZ, the compressive yield strength increased $40 \mathrm{MPa}$ due to the increase of the sulfur content from 0.02 to $0.1 \mathrm{wt} \%$ and the combined forming of precipitations. Furthermore, the compressive yield strength of the steel increased by $140 \mathrm{MPa}$ due to the addition of 10 vol\% Mg-PSZ [23].

In addition to the adjustment of particle sizes of matrix and reinforcing powder, a possibility to avoid clustering of the ceramic is high energy ball milling. By this intensive milling, the Mg-PSZ is knead into the steel matrix and distributed more homogeneously (Fig. 9.3). Furthermore, the steel matrix is strongly deformed. Thus, the steel recrystallizes during sintering and becomes very fine grained [24]. The steel matrix exhibits an average grain diameter of approximately $1.4 \mu \mathrm{m}$ (determined by EBSD) after ball milling at $250 \mathrm{rpm}$ and sintering at $1100{ }^{\circ} \mathrm{C}$ and $5 \mathrm{~min}$ dwell time (composite contains 5 vol\% Mg-PSZ Z1 and TRIP steel S1) [18]. If the composite powder was mixed at $100 \mathrm{rpm}$ and sintered under the same conditions, the average grain diameter was $2.4 \mu \mathrm{m}$ [18]. Furthermore, shrinkage rate is drastically increased due to the higher number of dislocations and vacancies within the steel matrix as
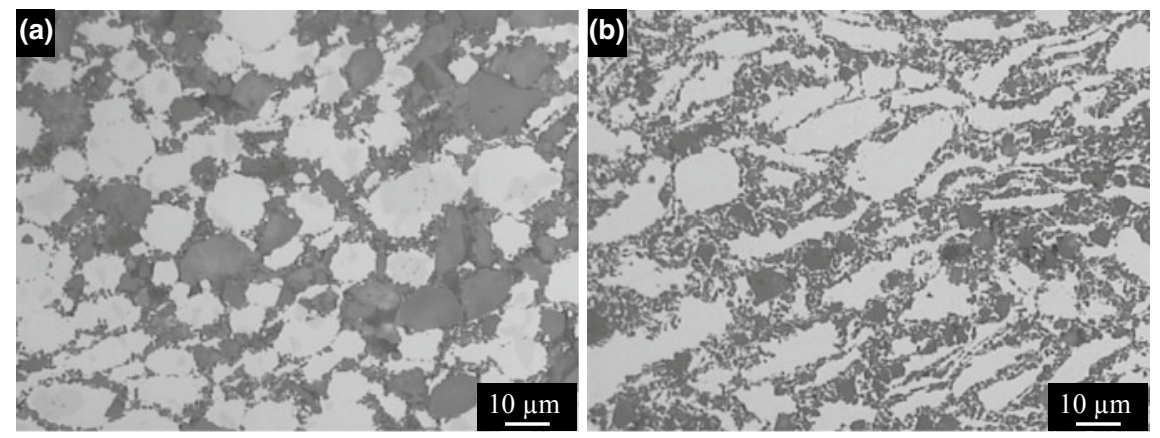

Fig. 9.3 Microstructure of a TRIP matrix composite, reinforced with 40 vol\% Mg-PSZ (S1, Z1) after sintering by FAST, powder milled with a $100 \mathrm{rpm}$ and $\mathbf{b} 250 \mathrm{rpm}$ 
a result of the milling process. Therefore, the necessary temperature for sintering decreases about $75 \mathrm{~K}$, if the powder was milled at $250 \mathrm{rpm}$ [18, 24]. However, due to the homogeneous distribution of the Mg-PSZ within the steel matrix, more MgPSZ/steel interfaces exist. Hence, the area where the Mg-ions have the possibility to diffuse into the steel matrix is larger and more Mg-PSZ destabilizes during sintering. Depending on the used powder batch and sintering parameters, approximately 35$45 \mathrm{vol} \%$ of the Mg-PSZ are in the monoclinic phase after sintering [18, 24]. Due to the better clamping of the Mg-PSZ with the steel matrix, the interfacial strength is increased and results in an improved transmission of loading from the steel matrix to the Mg-PSZ. Thus, the content of stress-induced phase transformation increases and 40-55 vol\% of the Mg-PSZ transform stress-induced into the monoclinic phase under compressive loading $[18,24]$. All in all, the compressive strength was drastically affected by the used TRIP steel and the Mg-PSZ content. For a composite (consisting of S1 and Z2) reinforced with 40 vol\% Mg-PSZ, the $1 \%$ compressive yield strength increased from 776 to $1328 \mathrm{MPa}$, if the rotation speed was increased from 100 to $250 \mathrm{rpm}$. The effect of powder processing was further illustrated by the shift of $1 \%$ compressive yield strength of a composite with 5 vol\% Mg-PSZ (S1 and Z1) from $540 \mathrm{MPa}(100 \mathrm{rpm})$ to $625 \mathrm{MPa}(250 \mathrm{rpm})$ [18]. Even further improvement to $700 \mathrm{MPa}$ was possible by adjusting sintering parameters [18].

\subsubsection{Influence of Sintering Parameters on the Microstructure and the Mechanical Properties of the Sintered Composite}

Besides the requirements of the initial powders to achieve a high-strength material, which has the ability to undergo phase transformations under mechanical loading, the coordination of the sintering process is decisive for the microstructural evolution and the mechanical properties of the sintered material. In the case of FAST, sintering temperature, heating rate, cooling rate, dwell time, pressure and setting of die and punches influence the result of the sintering process.

If the pulsing of the current exhibits an explicit effect on densification behavior and the material properties, is discussed controversially in literature. Chakraborty et al. for example found a decreased relative density for $\mathrm{ZrB}_{2}$ after sintering by FAST, if the off time of the pulse profile exceeded the on time [25]. Shen et al. reported a slight increase of the temperature which is needed for densification of alumina with increasing on:off pulse ratio [26]. Belmonte et al. found an increase in peak voltage and a shift of the maximum shrinkage rate to lower temperature with decreasing number of pulses and increasing off time during sintering of silicon nitride [27]. Moreover, an influence of the on:off ratio on the presence of an alumina layer on the surface of aluminum powder particles, and on the reactivity of aluminum with carbon was determined by Lalet et al. [28]. As well, they found melting of aluminum already at $500{ }^{\circ} \mathrm{C}$, which is $150 \mathrm{~K}$ below the actual melting point of 
aluminum, if the dc on:off ratio was $<1$ [28]. Furthermore, Jiang et al. reported an improved interfacial reaction between aluminum and $\mathrm{Si}_{3} \mathrm{~N}_{4}$ in an aluminum matrix composite with decreasing pulse ratio. However, the mechanical properties of this composite were best at a short pulse time and an dc on:off ratio $>1$ [29]. In contrast, Xie et al. investigated the influence of the frequency of pulsed electric current during sintering on the mechanical and electrical properties of aluminum and found no effect [30]. Furthermore, Chen et al. proved, that the pulse pattern of the current does not influence the formation and growth of an reaction layer between Mo and Si [31].

Using a composite powder (mixed at $100 \mathrm{rpm}$ ), consisting of $40 \mathrm{vol} \% \mathrm{Mg}-\mathrm{PSZ}$ (Z1) and $60 \%$ of TRIP steel (S1), for sintering by FAST, several pulse pattern were tested $(3: 1 \mathrm{~ms} ; 12: 2 \mathrm{~ms} ; 27: 9 \mathrm{~ms}, 30: 2 \mathrm{~ms})$ during heating up to $1020{ }^{\circ} \mathrm{C}$ and a dwell time of $5 \mathrm{~min}$ (51 MPa uniaxial compression, $20 \mathrm{~mm}$ sample diameter) using a FAST device Dr. Sinter 2050 (Sumitomo Coal Mining Co., Ltd., Japan). However, no obvious effect of pulse pattern on densification, grain size and phase fraction was detected. Only temperature measurements during heating to $950{ }^{\circ} \mathrm{C}$ in a drill hole to the center of a densified steel sample (S1) and at the surface of the surrounding graphite die indicated a slight increase in temperature deviation with increasing off time. In this case, the sample center was hotter than the die, whereas the die temperature was the control variable. Hence, a temperature deviation of $33 \pm 7 \mathrm{~K}$ was indicated for a pulse pattern of $27 \mathrm{~ms}$ : $9 \mathrm{~ms}$ while all remaining pulse pattern lead to a deviation of approximately $21 \pm 5 \mathrm{~K}$.

To create a composite material by FAST, it is advisable to understand the sintering behavior of the composite constituents first. Especially for such different composite partners like steel and ceramic, it is necessary to find a parameter range, where both constituents sinter.

Independent of the heating rate, the TRIP steel (S1) begins to shrink between 550 and $600{ }^{\circ} \mathrm{C}$ (Fig. 9.4) [1, 18]. Above $1100{ }^{\circ} \mathrm{C}$, the TRIP steel starts to melt

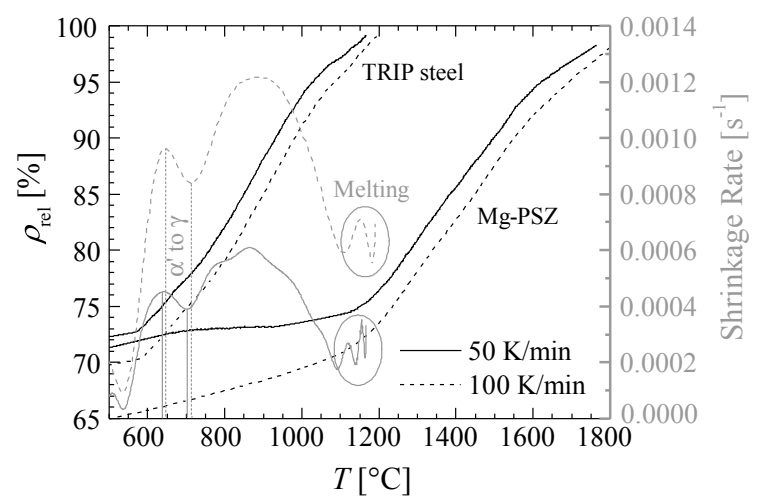

Fig. 9.4 Increase of relative density $\rho_{\text {rel }}$ and evolution of shrinkage rate with temperature $T$ of TRIP steel (S1) and Mg-PSZ (Z1) at a constant pressure of $51 \mathrm{MPa}$ 
[18] while the actual melting point of this steel is at $1416^{\circ} \mathrm{C}$ [32]. The melting of the steel at lower temperatures during FAST is a result of graphite diffusion from the die into the sample during sintering. Due to the increase of carbon content, the melting point is drastically reduced. Furthermore, the temperature is measured by a pyrometer inside a hole in the graphite punch, $5 \mathrm{~mm}$ away from the sample surface. Thus, the actual temperature inside the sample is going to be higher than the measured temperature. Hence, the maximum temperature to sinter TRIP steel in this sintering setup is $1100{ }^{\circ} \mathrm{C}$. Mg-PSZ, however, begins to shrink at a temperature slightly above $1100{ }^{\circ} \mathrm{C}$ (Fig. 9.4) and its optimum sintering temperature is between 1400 and $1600{ }^{\circ} \mathrm{C}$ [18]. With increasing heating rate, shrinkage rate increased [18]. Thus, a higher heating rate of $100 \mathrm{~K} / \mathrm{min}$ is beneficial. However, caused by the melting of the TRIP steel, the maximum sintering temperature to densify the composite has to be $1100{ }^{\circ} \mathrm{C}$. Higher temperatures are possible for the sintering of composites. However, the graphite die and the graphite punches are destroyed by the occurring steel melt. Besides, the steel melt partly flows out of the die. Furthermore, clustering of $\mathrm{Mg}$-PSZ has to be avoided due to the poor sintering of $\mathrm{Mg}$-PSZ at $1100{ }^{\circ} \mathrm{C}$.

With increasing temperature, not only shrinkage occurs, but phase transformation as well. For example, $\alpha^{\prime}$-martensite was generated during milling due to deformation by the milling balls. During sintering, the $\alpha^{\prime}$-martensite transforms into austenite while heating. For the steel S1, the temperature range for transformation is between 650 and $730{ }^{\circ} \mathrm{C}$ (Fig. 9.4) [1, 18]. This effect is marked by a flattened region in the relative density-temperature-curve and a decrease in shrinkage rate (Fig. 9.4). To prove this fact, bulk samples, where first $70 \mathrm{vol} \% \alpha^{\prime}$-martensite were formed by compressive deformation at $-196{ }^{\circ} \mathrm{C}$, were afterwards heated to 700 and $850{ }^{\circ} \mathrm{C}$ in a FAST device. While only $10 \mathrm{vol} \% \alpha^{\prime}$-martensite remained within the sample heated to $700{ }^{\circ} \mathrm{C}, 99 \%$ austenite were measured after heating to $850{ }^{\circ} \mathrm{C}[1,18]$.

The Mg-PSZ undergoes a phase transformation during sintering, as well. While the composite powder with 40 vol\% Mg-PSZ (consisting of S1 and Z1) exhibited $18 \mathrm{vol} \%$ monoclinic phase, no monoclinic phase was indicated by XRD after heating to $1100{ }^{\circ} \mathrm{C}$ without applying a dwell time. Even after sintering at $1100{ }^{\circ} \mathrm{C}$ of pure Mg-PSZ (Z1) powder with initially 10 vol\% monoclinic phase, no monoclinic phase remained [18]. This is in accordance with Berek et al., who found a phase transformation from monoclinic to tetragonal phase of Mg-PSZ within the temperature range of 700-1200 ${ }^{\circ} \mathrm{C}$ [33]. However, as already mentioned, if Mg-PSZ is in contact with steel, the $\mathrm{Mg}$-ions diffuse into the steel matrix and Mg-PSZ destabilizes. This effect is intensified with increasing temperature due to the rise in diffusion rate. Thus, $28 \mathrm{vol} \%$ monoclinic Mg-PSZ were determined within the Mg-PSZ of the composite reinforced with 5 vol\% Mg-PSZ (consisting of S1 and Z1) after sintering by FAST at $1200{ }^{\circ} \mathrm{C}$ and only 11 vol\% monoclinic phase after sintering at $1100{ }^{\circ} \mathrm{C}$. In both cases, no dwell time was used and a pressure of $16 \mathrm{MPa}$ was applied [18]. An equal trend was indicated for a composite reinforced with 40 vol\% Mg-PSZ (consisting of S1 and Z1) using the same FAST conditions. While no monoclinic phase was detected after sintering at $1100{ }^{\circ} \mathrm{C}, 7 \mathrm{vol} \%$ of the $\mathrm{Mg}$-PSZ exhibited the monoclinic phase after densification at $1200{ }^{\circ} \mathrm{C}$ [18]. 
An increase of dwell time from 5 to $10 \mathrm{~min}$ had no influence on grain size distribution within the steel matrix of a composite with 5 vol\% Mg-PSZ (consisting of S1 and Z1) [24]. However, during the first five minutes, the grains of the steel matrix grew approximately $2 \mu \mathrm{m}$ and $4 \mu \mathrm{m}$ inside composites with 5 and $40 \mathrm{vol} \% \mathrm{Mg}$ PSZ (consisting of S1 and Z1), respectively [18]. An exponential reduction of grain growth during dwell time was already reported by Shen et al. [26]. Even though steel grains grow during dwell time and a decrease in composite strength is expected, the compressive yield strength of the composite slightly increased with dwell time. While it was only a slight increase in compressive yield strength and it was within standard deviation, statements concerning correlations between increase in compressive yield strength and dwell time have to be handled with care. However, due to the absence of a decline in compressive yield strength, it is to assume that an increase in dwell time causes an improved interfacial strength by diffusion processes, which counteracts a decline in compressive strength caused by grain growth [18]. This assumption can be confirmed by micrographs (Fig. 9.5) of compressed composites, which exhibit a large number of cracks at steel/Mg-PSZ interfaces, if they were sintered without a dwell time, and, which show particle cracking and only a few locations of delamination, if a dwell time of five minutes was applied.

As already mentioned, the monoclinic phase of the Mg-PSZ transforms during sintering into the tetragonal phase. However, due to the loss of $\mathrm{Mg}$-ions to the steel matrix, the Mg-PSZ destabilizes and more monoclinic phase is formed. These two processes are in the opposite direction. Thus, after sintering at $1100{ }^{\circ} \mathrm{C}$ without dwell time no monoclinic phase was indicated in the composite with TRIP steel matrix type S1 [18]. However, destabilization dominates during dwell time. Depending on the used steel matrix and the pre-treatment of the powder, 15-40 vol\% of the Mg-PSZ are in the monoclinic phase after sintering at $1100{ }^{\circ} \mathrm{C}$ and five minutes dwell time [16-18, 24].

The applied pressure during sintering by FAST has an extreme influence on densification. If a composite with 5 vol\% Mg-PSZ (consisting of S1 and Z1) is
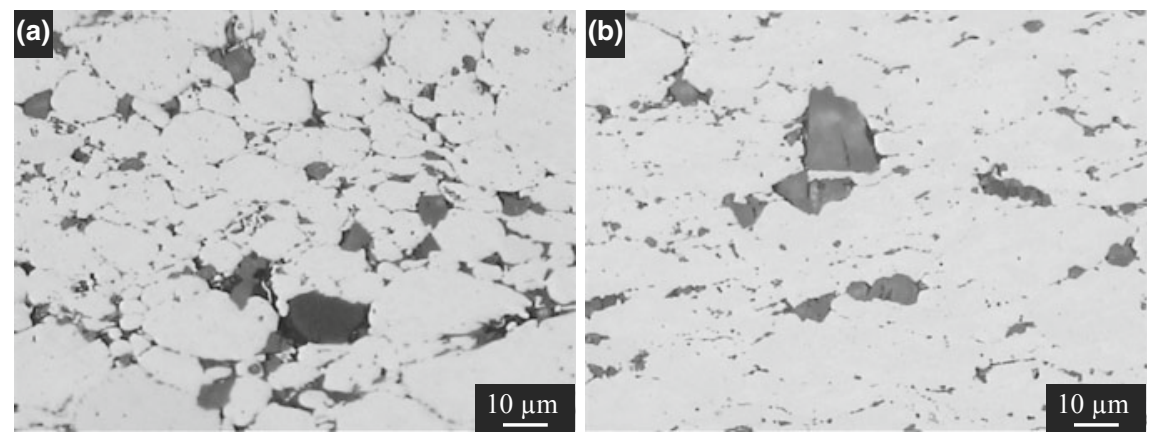

Fig. 9.5 Delamination and cracks after compressive deformation to $60 \%$ in a composite reinforced with 5 vol\% Mg-PSZ (consisting of S1 and Z1), sintered using FAST at $1100{ }^{\circ} \mathrm{C}$ under an uniaxial pressure of $16 \mathrm{MPa}$ and a no dwell time, $\mathbf{b} 5 \mathrm{~min}$ dwell time 
sintered at $1100{ }^{\circ} \mathrm{C}$ without dwell time and $16 \mathrm{MPa}$ applied pressure, the composite exhibits a relative density of $78 \%$. A relative density of $99 \%$ is realized, if a pressure of $51 \mathrm{MPa}$ is used. The relative density of a composite with $40 \mathrm{vol} \% \mathrm{Mg}-\mathrm{PSZ}$ (consisting of S1 and Z1) rises from 72 to $96 \%$ under the same FAST conditions, if the pressure is increased from 16 to $51 \mathrm{MPa}$ [18]. Due to an increased pressure, the particle contacts deform at elevated temperatures. Thus, porosity is reduced by creep of the material [18]. By increasing the pressure, it is possible to reduce the necessary maximum temperature for sintering and shrinkage starts at lower temperatures. This temperature difference increases with increasing Mg-PSZ content. If the pressure is increased from 16 to $51 \mathrm{MPa}$, onset temperature of shrinkage is reduced $45 \mathrm{~K}$ for a composite with 5 vol\% Mg-PSZ (consisting of S1 and Z1) and $250 \mathrm{~K}$ for a composite with 40 vol\% Mg-PSZ (consisting of S1 and Z1) [18]. The grain size of the steel matrix varies only for small Mg-PSZ contents with pressure. If a low pressure is applied during heating up and dwell time, the grain size becomes more heterogeneous. In this case, the porosity is quite high at the beginning of dwell time and only a few steel to steel contacts exist where the current passes through. Inside these preferred paths of the current, very large and elongated grains form, while the grains within electrically isolated areas remain small [18]. For higher Mg-PSZ contents, the influence of the pressure on grain growth decreases.

Due to the overheating at current paths during sintering at low pressure, Mg-PSZ particles, which are close to these current paths, destabilize. Thus, the monoclinic content within the Mg-PSZ of composites with a low Mg-PSZ content increases, if a low pressure is applied during sintering [18].

The interfacial strength between Mg-PSZ and steel of the composite is improved by applying a high pressure during sintering. Hence, composites (reinforced with 40 vol\% Mg-PSZ, consisting of S1 and Z1, 4\% porosity), which were sintered using a pressure of 16 and $51 \mathrm{MPa}$ exhibited a $0.5 \%$ compressive yield strength of 242 and $404 \mathrm{MPa}$, respectively. Furthermore, a maximum compressive deformation of $3 \%$ was reached, if a pressure of $51 \mathrm{MPa}$ was applied. In contrast, the composite sintered using a pressure of $16 \mathrm{MPa}$ fractured after $1 \%$ compressive deformation [18]. Certainly, both composites were indeed sintered at the same temperature of $1100{ }^{\circ} \mathrm{C}$ but with different dwell times to achieve the same porosity. While no dwell time was needed, if a pressure of $51 \mathrm{MPa}$ was applied, $5 \mathrm{~min}$ dwell time were necessary to achieve the same density at a pressure of $16 \mathrm{MPa}$. An increase in interfacial strength with prolongation of dwell time would be expected. However, the effect is not as strong as an increase in uniaxial pressure. Due to the improvement of interfacial strength by increasing the uniaxial pressure during sintering, slightly more strain-induced $\alpha^{\prime}$-martensite is formed during compressive deformation. However, this effect is characteristic for composites with a large Mg-PSZ content [18].

The stress-induced phase transformation of the Mg-PSZ is independent of $\mathrm{Mg}$ PSZ content of the composite, dwell time and applied pressure. After compressive deformation, a constant monoclinic content within the Mg-PSZ (Z1) of approximately 40 vol\% was measured within composites with a steel phase type S1 [18]. The initial monoclinic content after sintering depends on the used FAST parameters and the Mg-PSZ content. Thus, different amounts of stress-induced monoclinic phase 


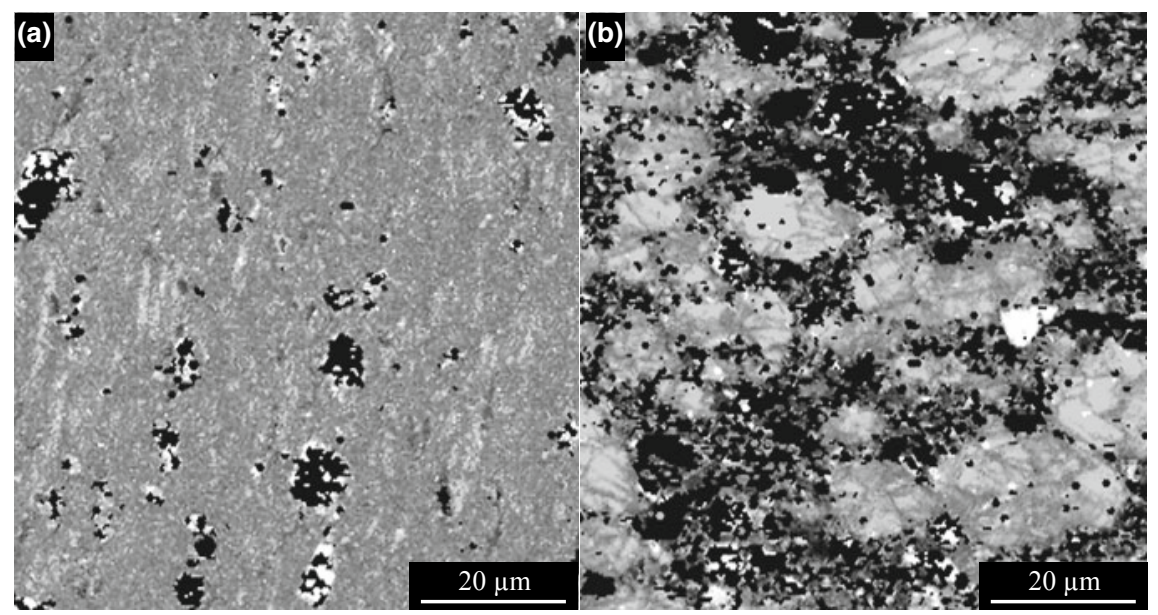

Fig. 9.6 EBSD analysis of the composite with a 5 vol\% Mg-PSZ after $60 \%$ compression and b $40 \mathrm{vol} \% \mathrm{Mg}$-PSZ after compression to fracture $\left(10^{-3} \mathrm{~s}^{-1}\right.$, grey: steel, white: monoclinic phase, black: tetragonal and cubic phase of the Mg-PSZ)

were formed during compressive deformation due to the chosen sintering parameters. However, it seems, that in this composites only $40 \mathrm{vol} \%$ of the Mg-PSZ were able to transform into the monoclinic phase (Fig. 9.6) [18].

If the stress-induced phase transformation of the Mg-PSZ influences positively the compressive flow behavior of the composite is questionable. Martin et al. [6] compared the compressive flow behavior of a composite reinforced with $5 \mathrm{vol} \%$ Mg-PSZ to a composite reinforced with 5 vol\% alumina. They explained the higher compressive strength of the composite, reinforced with Mg-PSZ, with the stressinduced phase transformation of Mg-PSZ. However, the interfacial strength between matrix and reinforcing phase is not the same in these composites. Furthermore, the median particle size of alumina was $1 \mu \mathrm{m}$ larger than that of the Mg-PSZ. Thus, the benefit by the stress-induced phase transformation is not entirely proven.

A simplified semiempirical model [see (9.3)] was developed on the basis of the rule of mixture [34], which considers the Mg-PSZ content, the Hall-Petch equation [19] for the influence of steel grain size, the equation of Haynes [35] taking into account the influence of the porosity, the equation of Olson and Cohen [36], which describes the $\alpha^{\prime}$-martensite evolution and the equation of Ludwik [37] for the reproduction of the flow behavior of the austenite. With this model, the compressive flow curve under quasi-static loading is well described for TRIP steel (S1) and composites (consisting of S1 and Z1) [18].

$$
\begin{aligned}
\sigma_{d}\left(\varepsilon_{w}\right)= & \left(1-V_{\mathrm{PSZ}}\right)\left(\left(\sigma_{00.5 \%, \mathrm{St}}+\frac{k}{\sqrt{d}}+A \cdot \varepsilon_{w}^{n}\right) \cdot\left(1-V_{\alpha}\right)+V_{\alpha} \cdot \sigma_{\alpha}\right) \\
& +V_{\mathrm{PSZ}} \cdot \sigma_{0 \mathrm{PSZ}}
\end{aligned}
$$




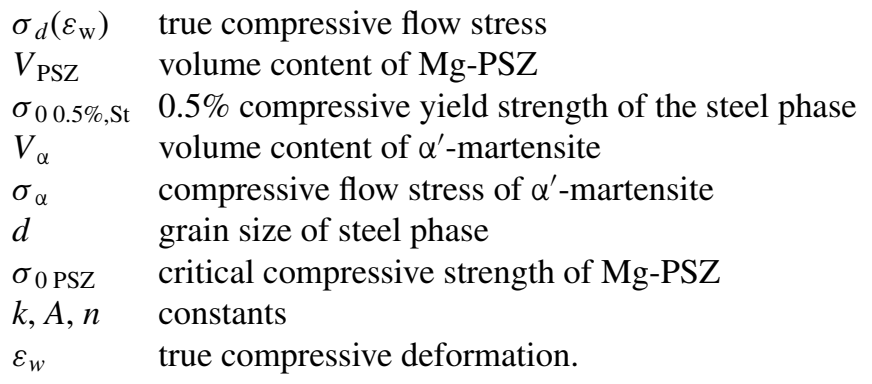

However, the stress-induced phase transformation was not taken into account in this model. Thus, the stress-induced phase transformation obviously does not increase the compressive flow strength, if the compressive flow curve is well described without a considered contribution by the stress-induced phase transformation.

Next to FAST parameters like temperature, dwell time and uniaxial pressure, the used die geometry influences the sintering result, as well. The influence of a varying die wall thickness on temperature distribution is well known [38]. But, if for example, the die wall thickness is constant and the sample diameter is increased, the relation between cross-sectional area of the die and cross-sectional area of the sample decreases. Hence, more electrical current is going to run through the electrical conductive sample instead through the die. Thus, the sample is more intensively heated up and onset of densification is shifted to lower temperature.

For example, intensive shrinkage of a composite, reinforced with 5 vol\% Mg-PSZ (consisting of S1 and Z1) and sintered in a die with $10 \mathrm{~mm}$ wall thickness, begins at $650{ }^{\circ} \mathrm{C}$, if the sample had a diameter of $20 \mathrm{~mm}$, and at $530{ }^{\circ} \mathrm{C}$, if the sample had a diameter of $40 \mathrm{~mm}$ [18]. Furthermore, using the same FAST parameters results in different relative densities. Due to the high energy input in larger samples, grain boundaries break away from pores and the pores get inside the grains, which makes it very difficult to close these [12]. However, the porosity increased only $2 \%$. The grain size of the steel phase was not influenced by the sample diameter [18]. Though, the destabilization of the Mg-PSZ was intensified by using a larger sample diameter and the combined increase in energy input inside the sample. The monoclinic content of the Mg-PSZ was doubled in composite samples with 5 vol\% Mg-PSZ (consisting of $\mathrm{S} 1$ and Z1) sintered with a diameter of $40 \mathrm{~mm}$ in comparison to those samples sintered with a diameter of $20 \mathrm{~mm}$ [18]. Due to no changes in steel grain size and only a slight difference in porosity, the compressive flow behavior was independent form the sample diameter [18]. However, it is advised to keep the relation between cross-sectional area of the die and cross-sectional area of the sample constant for upscaling, to receive a similar microstructure after sintering by FAST.

It is of great interest in research to determine the acting processes, which lead to densification during sintering by FAST. Kieback and Trapp evaluated several processes suggested in literature critically [39]. They summarized the acting processes to be local heating and melting of powder particle contacts, breaking of oxide layers by electrical breakdown, prevention of grain growth, plastic deformation, diffusion 
creep, grain boundary sliding, electron wind and thermodiffusion due to temperature gradients [39]. These processes are supported by a high heating rate and a high pressure [39].

Li et al. developed a way to determine shrinkage mechanisms during FAST. They adapted the load increasing test, which is used to calculate the strain rate exponent $m$ for creep tests [40]. Using this approach for pure steel and composites with 5 and $40 \mathrm{vol} \% \mathrm{Mg}$-PSZ (consisting of S1 and Z1) at a test temperature of $1000{ }^{\circ} \mathrm{C}$, strain rate exponents of $0.48 \pm 0.22$ and $0.47 \pm 0.05$ were identified for pure steel and composite with 5 vol\% Mg-PSZ, respectively. The composite with $40 \mathrm{vol} \% \mathrm{Mg}$-PSZ had a strain rate exponent of $0.32 \pm 0.10$. In this temperature range, mainly the steel is shrinking and the strain rate exponent describes the behavior of the steel phase. According to the calculated strain rate exponents, grain boundary sliding $(m=0.5)$ and potentially dislocation creep $(m=0.3, \ldots, 0.5)$ are the main occurring mechanisms [40].

The load increase test using pure $\mathrm{Mg}$-PSZ was carried out at $1400{ }^{\circ} \mathrm{C}$ and a strain rate exponent of $0.37 \pm 0.25$ was calculated. In this range of the strain rate exponent, sliding and climbing of dislocation dominates [41]. Taking into account the standard deviation, grain boundary sliding is possible as well [40]. At first, deformability of a ceramic seems unlikely, but for example Chen et al. proved that a deformation to $30 \%$ of zirconia at $1300^{\circ} \mathrm{C}$ is possible [42].

\subsubsection{Sintering of Functionally Graded Materials (FGM) by FAST}

Based on the presented results, FGMs with varying Mg-PSZ contents were developed. Therefore, several layer arrangements were tested using TRIP steel powder S5. For this purpose, composite powders with different amounts of Mg-PSZ (Z1) and TRIP steel were mixed and layered on top of each other to receive a gradation of Mg-PSZ along the height of the sample (diameter: $40 \mathrm{~mm}$ ). This gradation reached from 0 vol\% Mg-PSZ to 40 vol\% Mg-PSZ, while every layer should have a thickness of $1 \mathrm{~mm}$ after complete densification. Samples with layer arrangements of $0 \mathrm{vol} \%-20$ vol\%-40 vol\% Mg-PSZ, of 0 vol\%-10 vol\%-20 vol\%-40 vol\% Mg-PSZ and of 0 vol\%-10 vol\%-20 vol\%-30 vol\%-40 vol\% Mg-PSZ were generated (Fig. 9.7). To densify these layer systems, they were heated up with a heating rate of $100 \mathrm{~K} / \mathrm{min}$

(a)

\begin{tabular}{|c|}
\hline 40 vol. $\%$ \\
\hline 30 vol. $\%$ \\
\hline 20 vol. $\%$ \\
\hline 10 vol. $\%$ \\
\hline 0 vol. $\%$ \\
\hline
\end{tabular}

(b)

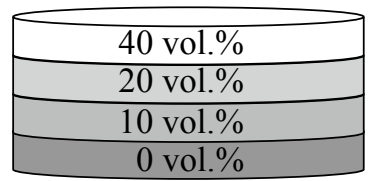

(c)

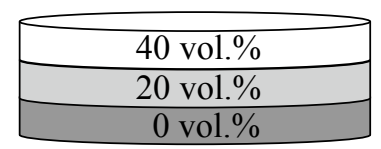

Fig. 9.7 Tested layering systems for the FGM with an Mg-PSZ content from 0 to $40 \mathrm{vol} \%$ 
to $1100{ }^{\circ} \mathrm{C}$ within a FAST device. During heating, the powder was uniaxially compressed while the pressure increased up to $100 \mathrm{MPa}$ and was kept constant during the dwell time of $10 \mathrm{~min}$.

Radwan et al. found a significant influence of layering system of FGMs consisting of stainless steel and alumina on densification behavior and residual stresses [43]. However, no distinct influence on mechanical properties and microstructure was indicated for the FGMs consisting of TRIP steel and Mg-PSZ. Independent of the layer system, the FGMs had a similar hardness, bending strength and grain size of the steel matrix. Except, the four layer system (0 vol\%-10 vol\%-20 vol\%-40 vol\% Mg-PSZ) was crack free after sintering, while cracks were found within the FGM with three and five layers. Thus, much higher thermal stresses were present in the three and five layer systems compared to the four layer system. These high thermal stresses caused these cracks. The reduction of thermal stresses is a function of $\mathrm{Mg}$ PSZ layer system. While the tested three layer and five layer systems exhibit a linear increase in Mg-PSZ content, the Mg-PSZ content of the four layer system follows an exponential function. These results confirm the assumption of Radwan et al., that an exponential increase in ceramic content leads to a reduction of thermal stresses [43].

As to be expected, the grain size of the steel matrix decreased with increasing ceramic content of the layer due to the pinning effect of the Mg-PSZ particles. Likewise hardness increased with Mg-PSZ content.

The FGMs exhibited a bending strength of $511 \mathrm{MPa}$ (steel layer on tensile stress). This is $100 \mathrm{MPa}$ larger than the bending strength of a steel matrix composite reinforced with $40 \mathrm{vol} \% \mathrm{Y}_{2} \mathrm{O}_{3}$-PSZ [44]. However, the FGMs were not completely dense. The porosity increased with Mg-PSZ content. Furthermore, the graphite dies do not withstand the high mechanical pressure of $100 \mathrm{MPa}$ during sintering by FAST at all times. Therefore, the pressure had to be decreased.

To completely densify the whole FGM especially applying a pressure $<100 \mathrm{MPa}$, the temperature distribution within the sintering setup has to be understood and systematically adapted. A vertical temperature gradient has to be expected by sintering of steel/ceramic FGMs using FAST due to the changing electrical conductivity along the sample height with changing ceramic content (Fig. 9.8). However,

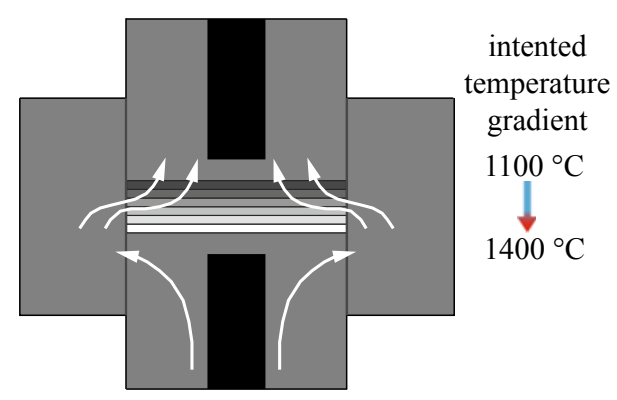

Fig. 9.8 Current path (marked by white arrows) through the sintering tool and the FGM and necessary sintering temperatures 
zirconia-rich regions need a temperature of $1200-1300^{\circ} \mathrm{C}$ [45] for nano sized powder and $1400-1600^{\circ} \mathrm{C}$ for coarser powder [18] to be compacted. Furthermore, steel melts at those temperatures. To densify steel using FAST, temperatures of $1000-1100{ }^{\circ} \mathrm{C}$ are required [1]. Thus, a temperature gradient is needed, where the ceramic-rich regions are hotter than the steel-rich regions.

To investigate the vertical temperature gradient caused by the changing ceramic content, an FGM with the layer arrangement 0 vol\%-5 vol\%-10 vol\%-30 vol\%60 vol\%-100 vol\% Mg-PSZ (from top to bottom, powders S6 and Z2) was sintered (maximum temperature $1100{ }^{\circ} \mathrm{C}$ measured in top punch, maximum pressure $51 \mathrm{MPa}$, dwell time $13 \mathrm{~min}$, heating rate $100 \mathrm{~K} / \mathrm{min}$ ). During densification, the temperature was measured by pyrometer and thermocouples (TCs) within drill holes inside the die $3 \mathrm{~mm}$ away from the inner die surface, on the level of the middle of the sample in vertical direction and $2 \mathrm{~mm}$ above and below the centric hole. These temperature measurements indicated a much higher temperature at the top, which was close to the steel-rich regions compared to the Mg-PSZ-rich regions at the bottom of the sample [46]. During dwell time, the top and bottom temperatures slightly converged and differed $\approx 20 \mathrm{~K}$ at the end of dwell time. Hence, the steel-rich regions are $\approx 20 \mathrm{~K}$ warmer than the ceramic-rich regions, while it has to be the other way around to densify the FGM properly.

Some researchers introduced vertical temperature gradients by using tapered dies $[9,47]$ and found a vertical temperature gradient of $220 \mathrm{~K}$. To obtain the required die geometry, extensive simulations and tests are necessary. Other researchers did not change the die geometry. They moved the sample from the die center to the bottom and placed the die directly on the lower larger punch to create a vertical temperature gradient within the sample [48, 49]. However, the temperature gradient varies strongly with the sintering material and the die geometry [50]. Vanmeensel et al. reported a strong increase in electrical resistivity with increasing number of surfaces [51] and therefore, with increasing number of graphite foils at the front surface of the sample. Hence, graphite foil can be used as heating element. To generate heat close to the ceramic-rich regions of the FGM in this study [46], two additional graphite foils were placed between graphite punch and 100\% Mg-PSZ layer. Thus, the temperature within the ceramic-rich region converged to the temperature of the steel-rich regions, as indicated by temperature measurements inside the die [46]. During dwell time, the temperature of the ceramic-rich region even exceeded the temperature of the steel-rich region to $10 \mathrm{~K}$ [46]. Already, these slight temperature changes led to a lower porosity, improved bending strength and hardness (Fig. 9.9) [46]. However, a higher temperature is needed in the ceramic-rich region.

Since the ceramic-rich regions sinter during dwell time, the temperature gradient has to be existent during dwell time, as well. Furthermore, temperature measurements directly inside the sample are necessary to understand the temperature evolution inside the sample. Only a few studies dealt with direct temperature measurement using homogeneous materials, especially at process temperatures at or above $1000{ }^{\circ} \mathrm{C}$. Temperature measurements utilizing TCs (at least one TC directly within the sample) were performed in the studies of Matsugi et al. [52] or Wang et al. [53]. 


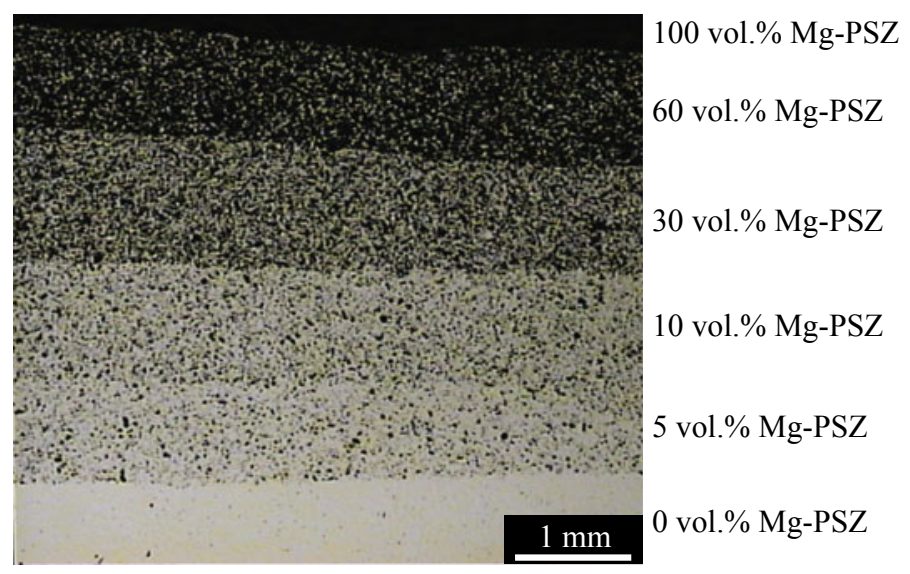

Fig. 9.9 FGM, sintered with additional graphite foils

Furthermore, the thermal insulation around the sintering tool influences the temperature distribution inside the sample. The application of thermal insulation by graphite felt as well as heating elements manufactured by CFRC and its influence on the temperature homogeneity within a conductive (austenitic steel) or non-conductive ( $8 \mathrm{~mol} \% \mathrm{Y}_{2} \mathrm{O}_{3}$ fully stabilized zirconia) sample was studied by Laptev et al. [54]. Particularly for large sample diameter $(\leq 50 \mathrm{~mm})$, the fully thermal insulation of the die was not sufficient to achieve an acceptable horizontal temperature gradient $(<20 \mathrm{~K})$ from the center to the edge of the (conductive) sample. Thus, further thermal insulation by the utilization of CFRC heating elements is required. In the case of non-conductive materials, an optimization (e.g. modification of the die thickness) of the sintering tool, in addition to the application of graphite felt and carbon fiber reinforced carbon (CFRC) heating elements, is often required to obtain an almost homogenous temperature distribution within the sample.

Thus, a further study concerning the temperature distribution within an FGM (consisting of S7 and Z3) during the FAST process dealt with the direct temperature measurement of the vertical temperature gradient of pre-sintered FGMs (at $1050{ }^{\circ} \mathrm{C}$ for $15 \mathrm{~min}$ ) during the dwell time at $1000{ }^{\circ} \mathrm{C}$ (duration: $8 \mathrm{~min}$ ). In reference [43] an equation for the calculation of the steel volume content of each layer within a steel/ceramic FGM is given. A total number of six layers, including the pure $\mathrm{Mg}$ PSZ and steel layer, was selected for the FMG sample (layer thickness: $1.5 \mathrm{~mm}$ ). For $P=2$ (material concentration exponent), a steel-rich concentration profile was received, leading to an ceramic volume content of the interlayers of 4, 16, 36 and 64 vol\% between the layers of pure steel and Mg-PSZ.

The direct temperature measurement using type S TCs took place within cylindrical bore holes (diameter: $3.5 \mathrm{~mm}$ ), which had an offset to each other of $90^{\circ}$. The TC-measured temperature $T_{\mathrm{TC}}$ was determined in the center of the sintering tool, above (M1), centered (M2) and below (M3) the FGM sample, which is shown in Fig. 9.10. Alumina tubes were used to protect the TCs from high electrical currents, 

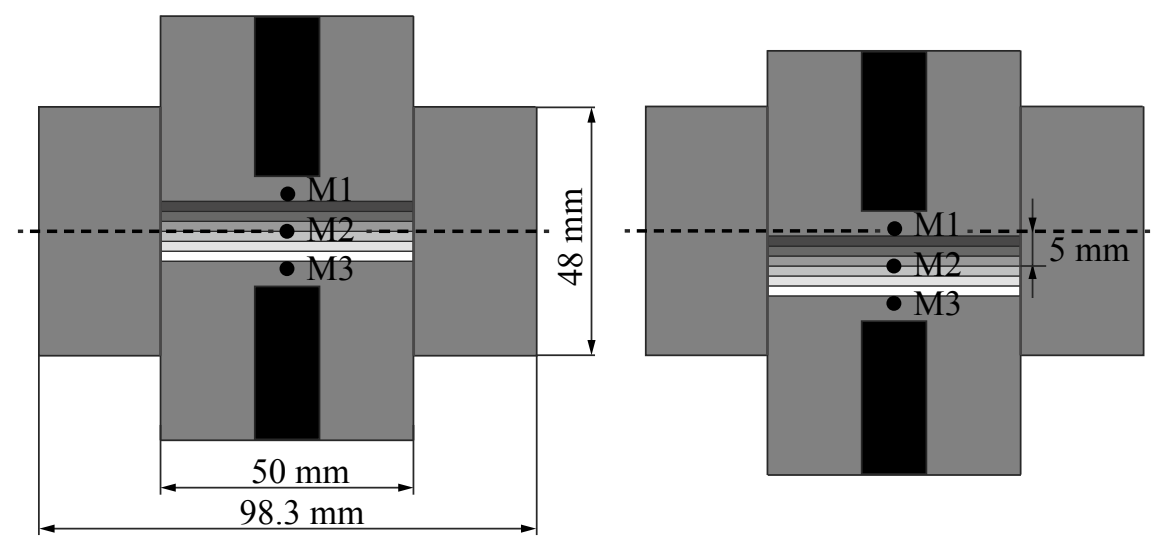

Fig. 9.10 Sintering tool setup, a symmetrical tool setup, b asymmetrical tool setup—FGM sample shifted by $5 \mathrm{~mm}$ downwards

carbonization or sintering to the sample surface. In addition to the experiments with a symmetrical sintering tool setup, asymmetrical sintering tool setups were investigated. For this purpose, the FGM sample was shifted by $5 \mathrm{~mm}$ upwards or downwards for both options-with the pure ceramic or steel layer on top.

For all temperature measurement experiments, the outside surface and the top and bottom side of the die were covered with graphite felt (SGL Group: Sigratherm GFA10) to reduce thermal radiation losses. Furthermore, the influence of CFRC discs on the temperature distribution during the SPS/FAST process was investigated.

In general, an 80-90 K higher $T_{\mathrm{TC}}$ in comparison to the pyrometer-measured process temperature $T_{\text {Pyro }}$ was determined for the symmetrical sintering tool setup at M1 independent of the sample arrangement (pure ceramic layer at the top or at the bottom) and the application of CFRC discs. Furthermore, the highest vertical temperature gradient of approximately $80 \mathrm{~K}$ existed for the symmetrical sintering tool setup using an FGM sample with the fully ceramic layer at the top without utilizing CFRC discs for this FAST process. For the same sintering tool, the vertical temperature gradient decreased to approximately $15 \mathrm{~K}$ by the application of CFRC discs for the sintering process. Generally, in consequence of the utilization of CFRC discs for the FAST process, the heat was retained in the sintering tool and the electrical power required for the FAST process decreased. Both, the symmetrical or asymmetrical sintering tool setups exhibited vertical temperature gradients $<40 \mathrm{~K}$ while using CFRC discs for the sintering process. Despite the application of an asymmetrical sintering tool setup without using CFRC discs for the SPS/FAST process, the vertical temperature gradient never exceeded $80 \mathrm{~K}$. Although, this temperature gradient is still not sufficient to sinter void free FGM, it is an improvement. 


\subsection{Conclusions}

The combination of TRIP steel with Mg-PSZ in a composite and additionally processing this composite by applying FAST resulted in a material with a high strength and a sufficient ductility. By carefully adapting sintering parameters, the material had the ability to undergo strain-induced (TRIP steel) and stress-induced (Mg-PSZ) phase transformations under compressive loading. How the condition of the composite powder and the setting of FAST parameters influence the microstructure and the mechanical properties of the composite is schematically shown in Figs. 9.11 and 9.12. Due to the very short sintering time, only a small amount of the Mg-PSZ transformed into the monoclinic phase during sintering and the steel matrix exhibited very fine grains. Thus, the composites had a high strength. The amount of strength, however, depends on many factors concerning the used parameters, powder characteristics and powder treatment in preparation of FAST. Thus, parameters have to be carefully aligned for every powder condition. However, porosity can remain in the material even after tuning of the sintering parameters, as recently shown on a PM X15CrNiMnN19-4-3 [55]. This steel has a high nitrogen content of $0.17 \mathrm{wt} \%$, which evaporates during sintering and remains partly as porosity ( $\approx 5 \mathrm{vol} \%$ pores $)$.

Even though the Mg-PSZ has the ability to transform stress-induced after processing by FAST, this stress-induced phase transformation seems to have no influence on flow behavior under compressive deformation. On the one hand, the transforming amount of the Mg-PSZ is very low. On the other hand, the very ductile steel matrix does not transfer all loading to the Mg-PSZ. Thus, composites with a steel matrix, which has a higher strength (e.g. PM X16CrNiMnSiN 15-3-3), are investigated currently in order to increase the strength due to the stress-induced phase transformation of the Mg-PSZ. However, even without an effect of the stress-induced phase transformation, already an addition of 5 vol\% Mg-PSZ to a TRIP steel matrix (S1, Z1) increases the specific energy absorption at dynamic deformation at room temperature by $5 \%[56]$.

So far, the introduced composites were carefully mechanically characterized by cyclic deformation [57] and by compression tests in a wide range of strain rates and temperatures $[16,17,56]$. Their corrosion behavior was investigated as well [58-60]. A detailed analysis of these results would go beyond the scope of the presented work. So far, weakly sintered ceramic clusters and a low interfacial strength between steel and Mg-PSZ are obstacles for a further improvement of the materials. Especially, the improved sintering of Mg-PSZ-rich layers for the development of FGM requires further research effort.

Acknowledgements The Authors would like to thank Prof. Zhijian James Shen from Stockholm University for his helpful advice and the possibility to carry out experiments using the FAST device (Dr. Sinter 2050, Sumitomo Coal Mining Co., Ltd., Japan) from his group. Furthermore, the authors would like to thank Dr. Tobias Dubberstein (subproject A2) for providing the steel powders with varying sulfur content and Michael Hötzel (subproject A3) for making steel powder, sieved to different particle fractions, available. The authors would like to thank the German Research Foundation (DFG) for supporting the investigations, which were part of the Collaborative Research Center TRIP-Matrix Composites (project number 54473466-SFB 799, subproject A6). 


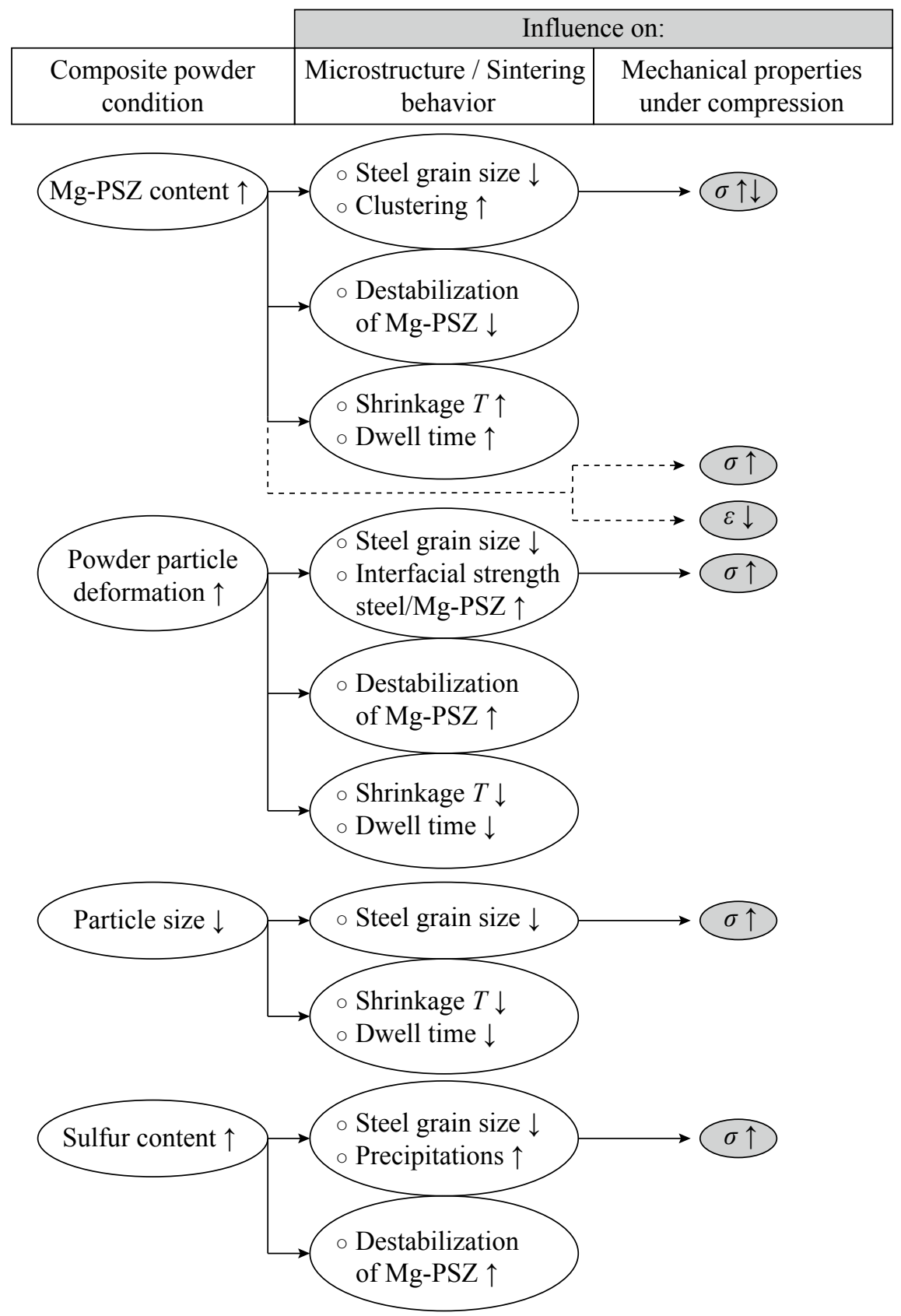

Fig. 9.11 Influence of composite powder condition on sintering behavior, microstructure and mechanical properties ( $T$ : temperature, $\varepsilon$ : ductility, $\sigma$ : compressive yield strength) 


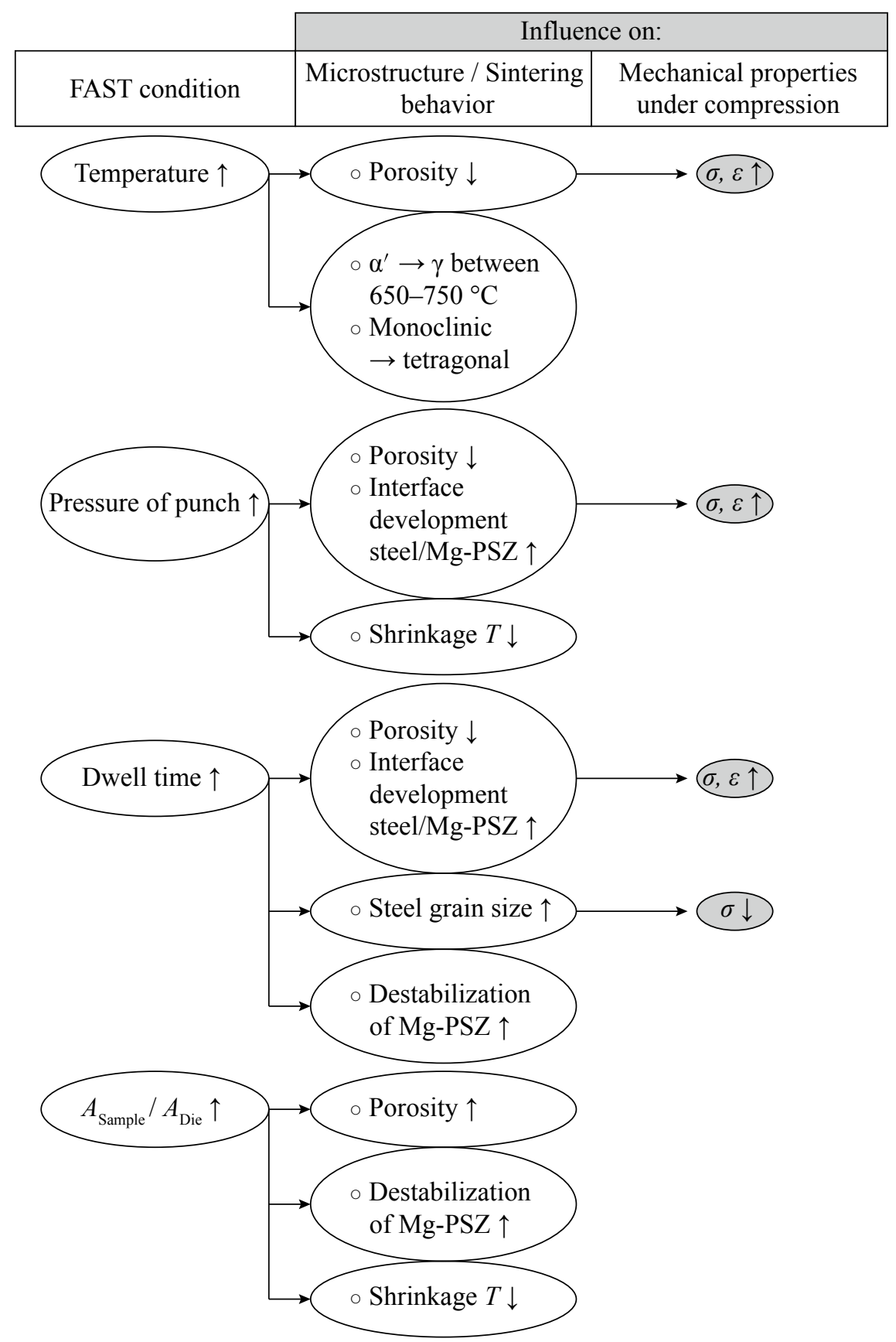

Fig. 9.12 Influence of FAST condition on sintering behavior, microstructure and mechanical properties $\left(A_{\text {Sample }}:\right.$ cross section of sample, $A_{\text {Die }}:$ cross section of die, $\alpha^{\prime}: \alpha^{\prime}$-martensite content, $\gamma$ : austenite content, $T$ : temperature, $\varepsilon$ : ductility, $\sigma$ : compressive yield strength) 


\section{References}

1. S. Decker, S. Martin, L. Krüger, Metall. Mater. Trans. A 47, 1 (2016)

2. J.A. Venables, Philos. Mag.: J. Theor. Exp. Appl. Phys. 7, 73 (2006)

3. O. Grässel, L. Krüger, G. Frommeyer, L. Meyer, Int. J. Plast 16, 10-11 (2000)

4. H. Salmang, H. Scholze, Keramik (Springer, Berlin, 2007)

5. J.R. Kelly, I. Denry, Dent. Mater. 24, 3 (2008)

6. S. Martin, S. Richter, S. Decker, U. Martin, L. Krüger, D. Rafaja, Steel Res. Int. 82, 9 (2011)

7. O. Guillon, J. Gonzalez-Julian, B. Dargatz, T. Kessel, G. Schierning, J. Räthel, M. Herrmann, Adv. Eng. Mater. 16, 7 (2014)

8. Z.A. Munir, U. Anselmi-Tamburini, M. Ohyanagi, J. Mater. Sci. 41, 3 (2006)

9. M. Tokita, Mater. Sci. Forum 308-311 (1999)

10. L. Hälldahl, M. Nygren, Mater. Sci. Forum 492-493 (2005)

11. K. Ichikawa, S. Murakami, S. Miyamoto, Y. Nakayama, M. Tokita, Mater. Sci. Forum 423-425 (2003)

12. R.M. German, Powder Metallurgy and Particulate Materials Processing (Metal Powder Industries Fed, Princeton, NJ, 2005)

13. M.N. Rahaman, Ceramic Processing and Sintering, 2nd edn. (CRC Press (Taylor \& Francis), Boca Raton, 2003)

14. H. Berek, A. Yanina, C. Weigelt, C.G. Aneziris, Steel Res. Int. 82, 9 (2011)

15. C. Weigelt, S. Giersberg, C. Wenzel, C.G. Aneziris, Adv. Eng. Mater. 12, 6 (2010)

16. L. Krüger, S. Decker, R. Ohser-Wiedemann, D. Ehinger, S. Martin, U. Martin, H.J. Seifert, Steel Res. Int. 82, 9 (2011)

17. S. Decker, L. Krüger, S. Richter, S. Martin, U. Martin, Steel Res. Int. 83, 6 (2012)

18. S. Decker, Entwicklung der Mikrostruktur und der mechanischen Eigenschaften eines Mg-PSZpartikelverstärkten TRIP-Matrix-Composits während Spark Plasma Sintering, Dissertation, TU Bergakademie Freiberg (Logos Berlin, Berlin, 2015)

19. E.O. Hall, Proc. Phys. Society. Sect. B 64, 9 (1951)

20. S. Decker, L. Krüger, Mater. Sci. Eng. A 761 (2019)

21. S. Martin, Deformationsmechanismen bei verschiedenen Verformungstemperaturen in austenitischem TRIP/TWIP-Stahl, Dissertation, TU Bergakademie Freiberg (Freiberger Forschungshefte TU Bergakademie Freiberg, Freiberg, 2014)

22. S. Decker, K. Lange, L. Krüger, T. Dubberstein, Steel Res. Int. 86, 5 (2015)

23. S. Decker, K. Lange, T. Dubberstein, L. Krüger, Adv. Eng. Mater. 17, 9 (2015)

24. S. Decker, L. Krüger, J. Compos. Mater. 50, 13 (2015)

25. S. Chakraborty, A.R. Mallick, D. Debnath, P.K. Das, Int. J. Refract. Metals Hard Mater. 48 (2015)

26. Z. Shen, M. Johnsson, Z. Zhao, M. Nygren, J. Am. Ceram. Soc. 85, 8 (2002)

27. M. Belmonte, M.I. Osendi, P. Miranzo, Scripta Mater. 65, 3 (2011)

28. G. Lalet, H. Kurita, T. Miyazaki, A. Kawasaki, J.-F. Silvain, J. Mater. Sci. 49, 8 (2014)

29. H. Jiang, Z. Xu, Z. Xiu, L. Jiang, H. Gou, C. Zhou, G. Wu, J. Alloy. Compd. 763 (2018)

30. G. Xie, O. Ohashi, K. Chiba, N. Yamaguchi, M. Song, K. Furuya, T. Noda, Mater. Sci. Eng., A 359, 1-2 (2003)

31. W. Chen, U. Anselmi-Tamburini, J.E. Garay, J.R. Groza, Z.A. Munir, Mater. Sci. Eng., A 394, $1-2(2005)$

32. T. Dubberstein, M. Hötzel, R. Hagemann, P. Heller, P.R. Scheller, Steel Res. Int. 82, 9 (2011)

33. H. Berek, C.G. Aneziris, C. Wenzel, T. Westphal, W. Schärfl, Refractories Worldforum 3, 3 (2011)

34. N. Chawla, K.K. Chawla, Metal Matrix Composites, 2nd edn. (Springer, New York, 2013)

35. R. Haynes, Met. Powder Rep. 46, 2 (1991)

36. G.B. Olson, M. Cohen, Metall. Trans. A 6, 4 (1975)

37. P. Ludwik, Elemente der technologischen Mechanik (Springer, Berlin, 1909)

38. J. Räthel, M. Herrmann, W. Beckert, J. Eur. Ceram. Soc. 29, 8 (2009) 
39. B. Kieback, J. Trapp, in Sintern - der zentrale Prozess der Pulvermetallurgie, ed. by H. Kolaska (Heimdall, Hagen, 2011), p. 47

40. W. Li, E.A. Olevsky, J. McKittrick, A.L. Maximenko, R.M. German, J. Mater. Sci. 47, 20 (2012)

41. J. Weertman, Trans. ASM 61 (1968)

42. I.-W. Chen, L.A. Xue, J. Am. Ceram. Soc. 73, 9 (1990)

43. M. Radwan, M. Nygren, K. Flodström, S. Esmaelzadeh, J. Mater. Sci. 46 (2011)

44. K. Tohgo, T. Kawaguchi, Key Eng. Mater. 297-300 (2005)

45. J. Langer, M.J. Hoffmann, O. Guillon, J. Am. Ceram. Soc. 94, 1 (2011)

46. S. Decker, L. Krüger, Mater. Des. 115 (2017)

47. Z. Zhang, X. Shen, C. Zhang, S. Wei, S. Lee, F. Wang, Mater. Sci. Eng. A 565 (2013)

48. Y. Zhang, Z. Li, C. Li, Z. Yu, Ceram. Int. 41, 10 (2015)

49. M. Belmonte, J. Gonzalez-Julian, P. Miranzo, M.I. Osendi, Acta Mater. 57, 9 (2009)

50. C. Morin, S. Le Gallet, M. Ariane, F. Bernard, Ceram. Int. 42, 2 (2016)

51. K. Vanmeensel, A. Laptev, J. Hennicke, J. Vleugels, O. Van der Biest, Acta Mater. 53, 16 (2005)

52. K. Matsugi, H. Kuramoto, T. Hatayama, O. Yanagisawa, J. Mater. Process. Technol. 134, 2 (2003)

53. Y.C. Wang, Z.Y. Fu, Q.J. Zhang, Key Eng. Mater. 224-226 (2002)

54. A.M. Laptev, M. Bram, K. Vanmeensel, J. Gonzalez-Julian, O. Guillon, J. Mater. Process. Technol. 262 (2018)

55. M. Radajewski, R. Eckner, S. Decker, M. Wendler, L. Krüger, Adv. Eng. Mater. 21, 5 (2019)

56. S. Decker, L. Krüger, Mater. Des. 114 (2017)

57. A. Glage, S. Martin, S. Decker, C. Weigelt, M. Junghanns, C.G. Aneziris, U. Martin, L. Krüger, H. Biermann, Steel Res. Int. 83, 6 (2012)

58. M. Mandel, L. Krüger, S. Decker, Corros. Sci. 90 (2015)

59. M. Mandel, L. Krüger, S. Decker, Mater. Corros. 66, 12 (2015)

60. M. Mandel, L. Krüger, S. Decker, Mater. Werkst. 46, 10 (2015)

Open Access This chapter is licensed under the terms of the Creative Commons Attribution 4.0 International License (http://creativecommons.org/licenses/by/4.0/), which permits use, sharing, adaptation, distribution and reproduction in any medium or format, as long as you give appropriate credit to the original author(s) and the source, provide a link to the Creative Commons license and indicate if changes were made.

The images or other third party material in this chapter are included in the chapter's Creative Commons license, unless indicated otherwise in a credit line to the material. If material is not included in the chapter's Creative Commons license and your intended use is not permitted by statutory regulation or exceeds the permitted use, you will need to obtain permission directly from the copyright holder. 